Short Communication

\title{
COMPARISON OF TREATMENT OUTCOME OF ANTIHYPERTENSIVE DRUGS IN THE MANAGEMENT OF PREGNANCY INDUCED HYPERTENSION
}

\author{
SIVAKUMAR VELUSAMY \\ Department of Pharmacy Practice, PSG College of Pharmacy, Peelamedu, Coimbatore, Tamilnadu 641004, India \\ Email: sivavega@gmail.com
}

Received: 26 Oct 2016 Revised and Accepted: 09 Jan 2017

\begin{abstract}
This study was aimed to find out the differences in the pregnancy outcome of PIH women treated with the antihypertensive drugs methyldopa and nifedipine. The prospective observational study was conducted in a multi specialty hospital at Coimbatore with 161 PIH diagnosed women. Women were categorised into the no-drug group, methyldopa group, nifedipine group and methyldopa with nifedipine group. All the women were monitored from diagnosis to delivery. The maternal and neonatal data were collected and analysed. The drugs were significantly controlled the blood pressure (BP) from base to end $(\mathrm{P}<0.001)$. There was no significant difference in the reduction of BP between the drugs. Cesarean delivery $(>90 \%)$ and preterm delivery were high across all the groups. No significant difference was seen between these groups. The AGA (Average for gestational age) babies were significantly higher with a no-drug group (83\%) and lower with nifedipine group (40\%). Two women were reported with HELLP syndrome in methyldopa with nifedipine group. No significant difference was found in terms of pregnancy outcome between these groups except for eclampsia and AGA. Eclampsia was affected more with $14 \%$ in methyldopa with nifedipine group. We found similar outcomes; there were no significant changes between methyldopa, nifedipine, and the no-drug treatment. The antihypertensive drugs nifedipine and methyldopa both were significantly reduced the BP. The maternal and neonatal complications were similar between these two drugs. No beneficial effect can be identified one over another.
\end{abstract}

Keywords: Antihypertensive drugs, Methyldopa, Nifedipine

(C) 2016 The Authors. Published by Innovare Academic Sciences Pvt Ltd. This is an open access article under the CC BY license (http://creativecommons.org/licenses/by/4. 0/)

DOI: http://dx.doi.org/10.22159/ijpps.2017v9i3.15889

Pregnancy-induced hypertension (PIH) is associated with the various problems in pregnancy outcome. The complications of high blood pressure (BP) during pregnancy are detrimental [1]. The elevated or uncontrolled BP leads to early and cesarean delivery also caused various complications to both mother and fetus. Indeed, the $\mathrm{PIH}$ resolves postpartum it causes various maternal and fetal morbidity and mortality [2]. Growth retardation and fetal mortality are the serious complications in PIH pregnancy. The development of $\mathrm{PIH}$ often required medications to control the BP. Antihypertensive drugs are used to control the BP within the normal range which further reduces the PIH related complications. Although various drugs are used to treat the $\mathrm{PIH}$, the benefits of antihypertensive medication in PIH is inconsistent [3] and the use of antihypertensive medication as well as treatment targets in PIH remains controversial [4]. The chosen drug should be safe and effective to both mother and fetus in terms of reduction in PIH complications. Hence this study was planned to find out the differences in treatment outcome between the different types of antihypertensive drugs used in the treatment of PIH.

The study was approved by the Institutional ethics committee (EC/AP/102/09-2009, Date: 12-08-2009) at kovai medical center and hospital, Coimbatore, Tamilnadu, India. The observational study was carried out at kovai medical center and hospital from January 2009 to December 2014. A pregnant woman diagnosed by a physician as PIH is the elementary criteria to include into the study. Informed consent was obtained from all the women who are included in the study. Antenatal, perinatal and neonatal data were collected from the patient medical records and from the hospital database. Diabetes mellitus, gestational diabetes mellitus, hypertension, renal disorder, autoimmune disease women were not included in the study.

The PIH diagnosed women were categorised according to the drug that they received for their treatment. The groups are Group 0women who received none of the drug, Group 1-women who received nifedipine, Group 2-women who received methyldopa and Group 3-women who received nifedipine and methyldopa. The baseline BP (taken at the time of PIH diagnosed) and end BP (mean of last $4 \mathrm{BP}$ value) were taken to analyze the effect of the drug on reduction of $\mathrm{BP}$.

Cesarean section, eclampsia, preterm delivery (delivery before 37 th week of gestation), apgar score $\leq 7$ at 1 st $\mathrm{min}$, low birth weight (LBW) (baby birth weight lower than 2500 grams), intrauterine growth restriction (IUGR) (baby birth weight is below the tenth percentile of the average for the gestational age), HELLP syndrome (hemolysis, elevated liver enzyme and low platelet count), small for gestational age (SGA) (baby birth weight, length or head circumference lies below the 10th percentile of weight for that gestational age) were considered as PIH associated pregnancy complications for the outcome analysis.

SPSS package version 20.0 for windows was used to do the statistical analysis. Paired ' $t$ ' test was used to find out the control of blood pressure level before and after treatment. One-way ANOVA was done to find out the significance of reduction of BP and outcome between the treatments of PIH. $\mathrm{P}$ value $(\mathrm{P}<0.05)$ was considered as significance.

Totally 161 eligible women were included in the study. Of which 161 women 30 women were received no drug (Group 0), 50 women have received nifedipine (Group 1), 46 women were received methyldopa (Group 2) and 35 women were received nifedipine+methyldopa (Group 3). Eighty-two percent of women were treated by drugs for PIH complication and $18 \%$ of women were not treated by any drugs. The drugs used for the treatment are methyldopa- $250 \mathrm{mg}, 500 \mathrm{mg}$ (28.35\%), nifedipine-5 mg, $10 \mathrm{mg}$ (26.73\%). Around 21\% of women received both the drugs methyldopa and nifedipine.

BP for all the women was regularly monitored and it was controlled well. Details were presented in table 1 . The mean baseline BP, taken at the time of PIH diagnosed was 128.30 $\pm 85.03(13.38 / 8.67)$, $135.49 / 90.11 \pm(18.03 / 10.72), \quad 133.10 / 89.23 \pm(14.28 / 10.36)$ and $134.40 / 88.91 \pm(15.33 / 10.47)$ for group $0,1,2$ and 3 respectively. For the entire group, BP was significantly reduced from baseline to end. All the drugs were significantly controlled the BP level from base to end. But there was no significant difference in the reduction 
of BP between the drugs. It was similar to a study done on the comparison of nifedipine with methyldopa in Srilanka on $126 \mathrm{PIH}$ patients where the systolic and diastolic BP for nifedipine and methyldopa were significantly reduced from base to end [5]. The same result found with the study conducted at a national university hospital, Singapore, concluded that short-term treatment with methyldopa significantly reduced the maternal blood pressure [6].

A study by Afzal Qasim et al. [7] and Deepanjali lomte [8] compared the effectiveness of BP control between labetalol and methyldopa in PIH women and reported that the labetalol shows better BP control than methyldopa. When compare the effect of methyldopa alone and methyldopa with nifedipine, the BP reduction was same.

A study by Jayasutha J et al. [9] reported that methyldopa is effective in controlling BP in mild hypertension in PIH and for moderate to severe hypertension methyldopa with nifedipine is effective. Contrary to above say the study by Ganeshan et al. reported that the BP control was better with nifedipine than methyldopa [10]. In our study, we found that there was no significant difference in the control of BP between nifedipine and methyldopa. Both drugs were produced the same effect on control of BP. The combination of methyldopa and nifedipine were also produced a similar effect on control of BP.

The pregnancy outcome details were given in table 2. Cesarean delivery was high across all the groups' women. Ninety-four percent of women given birth through cesarean delivery whereas only $6 \%$ of women delivered through vaginal. All the women in group 0 have given birth through cesarean delivery. No significant difference found between the groups for types of delivery $(\mathrm{P}>0.05)$. Preterm delivery was registered more; around $70 \%$ of delivery was preterm delivery. The mean delivery week for all the groups was before the $37^{\text {th }}$ week of gestation.

A total of $161 \mathrm{PIH}$ women was given birth to 168 infants. Two fetal deaths were reported, each one from nifedipine and methyldopa groups. IUGR has recorded $14 \%$ and $20 \%$ with methyldopa and nifedipine group. Around $50 \%$ of the babies were AGA with drug treatment group and more than $80 \%$ of babies were AGA with no drug group. The AGA babies were significantly higher with a no-drug group (83\%) and lower with nifedipine group (40\%). Around $40 \%$ of babies were SGA and $60 \%$ were LBW in drug treatment groups and no significant difference have been noted between these drugs group.

Two women were reported with HELLP syndrome in methyldopa with nifedipine group. The $1^{\text {st }}$ minute Apgar score below 7 was $15.6 \%$ with no-drug group whereas $36 \%$ and $41 \%$ of babies were scored below 7 with methyldopa and methyldopa with nifedipine group respectively.

Sibai et al. [11] reported that (compared 300 PIH women for the perinatal outcome of treatment by methyldopa versus no drug) the treatment with methyldopa did not improve the pregnancy outcome. The calcium channel blocker nifedipine controls the blood pressure as other anti-hypertensive drugs do, but the advantages over the other drugs to pregnancy outcome need to be established [12]. When compared to methyldopa the perinatal outcome was not changed with nifedipine; both drugs were given similar pregnancy outcome [5].

We also found the similar outcome as above mentioned; there were no significant changes in the outcome of PIH between the methyldopa, nifedipine, and no drug treatment. A study done on methyldopa versus no drug treatment in the management of mild preeclampsia showed that there was no much difference in the occurrence of IUGR between the methyldopa group and no drug treatment group [13]. We also found the same that there was no difference in the incidence of IUGR between the methyldopa group and no drug group.

Randomised clinical trial by Elhassan et al. [14] compared the treatment of preeclampsia between methyldopa and no drug found; eclampsia and perinatal death were more with treatment group than the non-treatment group. Similar results found in our study, the eclampsia rate was high with no drug compared to methyldopa group, but contrary to death, one perinatal death occurred with methyldopa group and nifedipine group against no perinatal death with no-treatment group.

A study by venkateswaramoorthy et al. reported that along with a marked reduction in BP maternal and neonatal complications were also reduced when methyldopa combined with nifedipine in the management of PIH [15]. We do found the same result that there was a good reduction in BP with the combination of methyldopa and nifedipine but the maternal and neonatal complications were not significantly changed when compared with individually treated groups. No significant difference was found in terms of pregnancy outcome between these drugs treatment except for eclampsia. Eclampsia was affected more with $14 \%$ in methyldopa with nifedipine group whereas no women were affected with eclampsia in the no-drug group.

Antihypertensive drugs play an important role in managing BP. Many trials have been demonstrated its efficacy, but it may cause adverse effects [16]. There was an adequate control of BP in the nodrug group and the maternal and neonatal outcomes were also good comparatively with other treatment groups.

The drug groups were also not developed any drug related problems. The maternal and neonatal outcomes were similar between these groups with adequate control of BP.

The antihypertensive drugs nifedipine and methyldopa both were significantly reduced the BP. The pregnancy outcomes in terms of perinatal complications were same between these two drugs. No beneficial effect can be identified one over another drug. The combined effects of these two drugs were also similar when given separately. The adequate BP control by any antihypertensive drugs may give good pregnancy outcome.

Table 1: BP values at various stages

\begin{tabular}{lllll}
\hline Measurement & Nifedipine (n=50) & Methyldopa (n=46) & Nife+M. dop (n=35) & No drug (n=30) \\
\hline Baseline BP mm/Hg & & & & $128.30 \pm 13.38$ \\
Systolic & $135.49 \pm 18.03$ & $133.10 \pm 14.28$ & $134.40 \pm 15.33$ & $85.03 \pm 8.67$ \\
Diastolic & $90.11 \pm 10.72$ & $89.23 \pm 10.36$ & $88.91 \pm 10.47$ & $131.80 \pm 15.45$ \\
$\begin{array}{l}\text { End BP mm/Hg } \\
\text { Systolic }\end{array}$ & $132.70 \pm 14.40$ & $132.46 \pm 14.08$ & $133.97 \pm 19.35$ & $88.50 \pm 11.52$ \\
Diastolic & $89.50 \pm 9.41$ & $87.95 \pm 9.19$ & $91.37 \pm 11.92$ & $130.00 \pm 15.31$ \\
Postpartum BP mm/Hg & & & \\
Systolic & $130.44 \pm 10.46$ & $130.43 \pm 8.58$ & $131.52 \pm 11.14$ & $84.63 \pm 6.19$ \\
Diastolic & $88.56 \pm 5.97$ & $85.62 \pm 6.80$ & $85.07 \pm 5.38$ & $\mathrm{P}=0.001^{*}$ \\
& $\mathrm{P}=0.001^{*}$ & $\mathrm{P}=0.000^{*}$ & $\mathrm{P}=0.000^{*}$ & \\
\hline
\end{tabular}

* $\mathrm{P}$ value is significant $(\mathrm{P}<0.05)$, Nife $+\mathrm{M}$. dop-Nifedipine and Methyldopa 
Table 2: Maternal and neonatal complications

\begin{tabular}{|c|c|c|c|c|c|}
\hline Complications & Nifedipine (n=50) \% & Methyldopa $(n=46) \%$ & Nife+M. dop $(n=35) \%$ & No drug $(n=30) \%$ & P Value \\
\hline Cesarean delivery & 94 & 91.3 & 94.28 & 100 & $P=0.454$ \\
\hline Vaginal delivery & 6 & 8.69 & 5.71 & 0 & $P=0.454$ \\
\hline Week of delivery & $34.45 \pm 3.26$ & $34.31 \pm 2.90$ & $35.71 \pm 2.37$ & $36.23 \pm 1.9$ & \\
\hline Term delivery & 32 & 41.30 & 25.71 & 46.66 & $P=0.265$ \\
\hline Preterm delivery & 69.26 & 60.41 & 75 & 56.25 & $P=0.376$ \\
\hline LBW & 61.53 & 56.25 & 61.11 & 43.75 & $P=0.457$ \\
\hline NBW & 40 & 45.65 & 40 & 60 & $P=0.313$ \\
\hline SGA & 42 & 37.5 & 41.66 & 21.87 & $P=0.234$ \\
\hline AGA & 40 & 60.86 & 54.28 & 83 & $\mathrm{P}=.002^{*}$ \\
\hline IUGR & 20 & 14.58 & 11.11 & 6.25 & $P=0.391$ \\
\hline Apgar $<7$ at $1^{\text {st }} \min$ & 36 & 25 & 41.66 & 15.62 & $P=0.101$ \\
\hline HELLP & 0 & 0 & 2 & 0 & $P=0.428$ \\
\hline Eclampsia & 6 & 2.17 & 14.28 & 6.66 & $\mathrm{P}=.049^{*}$ \\
\hline
\end{tabular}

* $\mathrm{P}$ value is significant $(\mathrm{P}<0.05)$, Nife+M. dop-Nifedipine and Methyldopa

\section{LIMITATION OF STUDY}

The study limited to the analysis of the occurrence of complications but not deals or interprets with remedial actions taken in the management of PIH. The combination of two drugs and cesarean delivery were may be the necessary actions to halt the adverse effect of PIH, but in our study, we considered the cesarean delivery as one of the maternal complications. The same way the combination of drugs been considered as a separate group for the analytical purpose.

\section{ACKNOWLEDGMENT}

I wish to thank kovai medical centre and hospital's labor ward nurses, $4^{\text {th }}$ south nurse station staffs and nurses and medical records department for their invaluable contributions to this study.

\section{Response to the comments of reviewers}

I have corrected the manuscript according to the reviewer's comments. I have marked text with red color wherever the changes been advised and corrected. I have cited one of the references from Asian journal of pharmaceutical and clinical research. I have changed the type of manuscript submission from original article to short communication. Subtitles were removed and the whole article is merged. To the last revision, I have followed one of the articles from your journal (vol 8, issue 11, 2016) to change my manuscript type to the short communication format, which was used all the subtitles. Hence I used the same format in my last revision. Here I have changed the format as per the instructions.

\section{CONFLICT OF INTERESTS}

\section{Declared none}

\section{REFERENCES}

1. Ghulmiyya L, Sibai B. Maternal mortality from preeclampsia/ eclampsia. Semin Perinatol 2012;36:56-9.

2. Walker JJ. Pre-eclampsia. Lancet 2000;356:1260-5

3. Blake S, MacDonald D. The prevention of the maternal manifestations of preeclampsia by intensive antihypertensive treatment. Br J Obstet Gynecol 1991;98:244-8.

4. Podymow T, August P. Antihypertensive drugs in pregnancy. Semin Nephrol 2011;31:70-85.

5. Jayawardana J, Lekamage N. A comparison of nifedipine with methyldopa in pregnancy induced hypertension. Celon Med J 1994;39:87-90.
6. Montan S, Anandakumar C, Arulkumaran S, Ingemarsson I, Ratnam SS. Effects of methyldopa on uteroplacental and fetal hemodynamics in pregnancy-induced hypertension. Am J Obstet Gynecol 1993;168:152-6.

7. Qasim A, Siddiqui MH, Salam JU, Nusrat U. Labetalol versus methyldopa: efficacy in pregnancy induced hypertension. Gomal J Med Sci 2014;12:233-6.

8. Deepanjali Lomte. An open-label, prospective, single-center study to evaluate the efficacy of methyldopa and labetalol in the treatment of patients with pregnancy-induced hypertension. World J Pharm Pharm Sci 2015;4:1235-41.

9. Jayasutha J, Ismail AM, Senthamarai R. Evaluation of the efficacy of methyldopa monotherapy and combination of therapy with nifedipine in pregnancy-induced hypertension. Der Pharm Lett 2011;3:383-7.

10. Ganeshan S, Narmadha MP, Paranjothy, Lakshminarayanan B, Alin, Bose J, et al. Comparison between nifedipine and methyldopa on blood pressure and fetal outcome in preeclampsia. Int J Adv Pharm Biol Sci 2012;2:191-8.

11. Sibai BM, Mabie WC, Shamsa F, Villar MA, Anderson GD. A Comparison of no medication versus methyldopa or labetalol in chronic hypertension during pregnancy. Am J Obstet Hynecol 1990;162:966-7.

12. Levin AC, Doering PL, Hatton RC. Use of nifedipine in the hypertensive diseases of pregnancy. Ann Pharmacother 1994;28:1371-8.

13. Suhonen L, Teramo K. Hypertension and pre-eclampsia in women with gestational glucose tolerance. Acta Obstet Gynecol Scand 1993;72:269-72.

14. Elhassan EM, Mirghani OA, Habour AB, Adam I. Methyldopa versus no drug treatment in the management of mild preeclampsia. East Afr Med J 2002;79:172-5.

15. Venkateswaramurthy N, John C, Perumal P. Study on antihypertensives in preeclampsia. Asian J Pharm Clin Res 2012;5:126-8.

16. Anderson NR, Undeberg M, Bastianelli KMS. Pregnancyinduced hypertension and preeclampsia: a review of current antihypertensive pharmacologic treatment options. Austin J Pharmacol Ther 2013;1:1-8.

\section{How to cite this article}

- Sivakumar Velusamy. Comparison of treatment outcome of antihypertensive drugs in the management of pregnancyinduced hypertension. Int J Pharm Pharm Sci 2017;9(3):287-289. 